\title{
La ética Vs. el abuso de la investigación clínica
}

\author{
Miguel Angel Alarcón Nivia*
}

\section{RESUMEN}

Se comentan en forma breve las más conocidas e infames investigaciones realizadas en humanos en aras de la ciencia. Se muestra la necesidad de crear y fortalecer los Comités de Etica en instituciones donde se investiga y se exponen las normas vigentes del Ministerio de Salud de Colombia que rigen los estudios con humanos y animales. Este documento está especialmente dirigido a los jóvenes investigadores que dan sus primeros pasos en el campo de la salud humana.

PALABRAS CLAVES: Investigación y ética, prisioneros judíos, experimentos en animales y humanos, Auschwitz, Mengele, gemelos, Estudio Tuskegee, Irradiación, Comités de ética.

\section{SUMMARY}

This paper show you the most known and infamous experiments on humans in name of science. It mention the necessity of Etical Committees, the guidelines of Ministerio de Salud de Colombia about investigation. This document is dedicated specially to young investigators in human health.

KEY WORDS: Investigation and ethics, jewish prisoners, experiments in animals and humans, Auschwitz, Mengele, twins, Tuskegee study, Irradiation, Committee of Ethics.

\section{Introducción}

Debemos reconocer que el siglo XX ha brindado grandes y rápidos avances en la investigación tecnológica para provecho del hombre, pero durante décadas han habido auténticos atentados a la dignidad de los seres humanos a los cuales se pretende favorecer.

Aunque en la actualidad las universidades colombianas con facultades de salud no pretenden formar un científico de cada egresado, brindan las herramientas para que todos tengan acceso a las leyes que rigen el proceso que comienza con la formulación de una pregunta y culmina con el planteamiento de una o varias respuestas. De esta práctica surgirán algunos expertos en el difícil arte de investigar, que quizá tuvieron su primera experiencia como parte de su entrenamiento en el postgrado.

Obtener respuestas válidas a partir de la aplicación de las herramientas estadísticas que brinda la epidemiología tiene muchos requisitos entre los cuales un ingrediente importante es la honestidad en la aplicación del método científico. "Si el hombre nació sin entender y si algún día morirá sin saber si ha entendido, debe al menos haber intentado saber con honestidad " (L.C. Tejerizo, 1979) (3).

Ginecólogo-Obstetra. Profesor de la Universidad Industrial de Santander. Miembro del Comité de Etica de la Investigación. Facultad de Salud. Fellow Epidemiología Clínica P.U. Javerianil. e-mail: mvamaya@b-manga.cetcol.net.co
Quien se soma por primera vez a esta nueva disciplina de la investigación debe emplear mucho tiempo y dedicación. Debe dar sus primeros pasos de manera lenta pero segura, mirando donde pone los pies, salvando a tiempo los escollos, utilizando las señales que han dejado marcadas quienes ya transitaron parte de ese camino.

Cuando un residente de las especialidades médicoquirúrgicas se enfrenta a la necesidad de iniciar o participar en una investigación clínica debe tener en cuenta que el beneficio buscado debe guiarse por los principios de respeto a la dignidad, protección a los derechos humanos y la minimización de los riesgos inherentes a la aplicación de un medicamento, la utilización de una prueba diagnóstica, la introducción de una variante quirúrgica o cualquiera otra intervención terapéutica.

\section{Los antecedentes de la investigación en humanos}

El interés por lo desconocido ha acompañado al hombre desde que hizo conciencia de su aparición sobre la tierra. No se conoce mucho sobre los comienzos de la investigación en seres humanos. Apenas se dispone de anécdotas de pensadores y escritores de la antigüedad.

En épocas pretéritas se lograron avances en el conocimiento de la fisiología humana y en la respuesta a diferentes medios físicos, químicos y psicológicos, pero con grave riesgo para la integridad de los investigados: Según Galeno, el rey Atalo III de Pérgamo experimentaba en el año 137 a. JC con venenos y antídotos en criminales condenados a muerte. A mediados del siglo 
XVI el sacerdote, anatomista y médico italiano Gabriello Fallopio recibió la orden y permiso del Gran Duque de Toscana de practicar disecciones a un criminal y aún de causarle la muerte como creyera conveniente. Este sujeto murió luego de recibir opio de manera experimental para ver el efecto sobre el paludismo que sufría (5).

En 1721 el rey Jorge I de Inglaterra ofreció el perdón a los criminales de Newgate que se dejaran aplicar un inóculo de viruela. Este experimento sirvió de ayuda al conocimiento sobre la vacunación contra este flagelo, pues los seis voluntarios sobrevivieron. Cuando el cólera asiático invadió a Europa en 1830, alguien propuso la teoría de que el corazón se comprimía por una fuerza centrípeta y que se debía disminuir su esfuerzo mediante la sangría. Así pues a las víctimas del cólera se sumaron los enfermos que morían desangrados. En 1865 Claude Bernard refiere en su libro "Introducción al estudio de la Medicina Experimental", que en el imperio persa los gobernantes entregaban a los médicos los cuerpos de los condenados a muerte para practicar la vivisección (disección en individuos vivos $)(2,4,6)$.

\section{Los autoexperimentos}

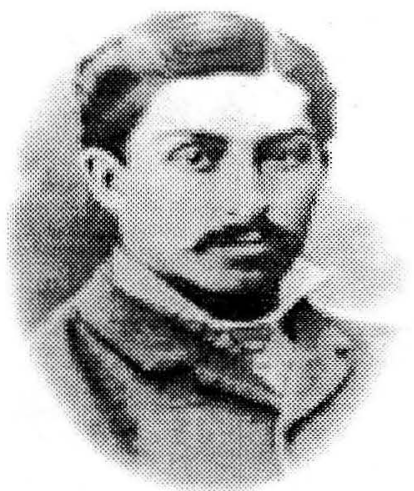

Foto de Daniel A. Carrión Figura 0007i01

Algunos experimentos han puesto en riesgo la integridad y la vida de los mismos investigadores: En 1885 falleció Daniel Alcides Carrión a los 26 años de edad, estudiante de medicina peruano al inocularse con secreciones de un paciente que tenía verruga peruana para ver si producía los mismos signos y síntomas de la fiebre de Oroya. Por este episodio se la llama fiebre de Carrión.

En 1903 Head se cor-

tó varios de sus nervios sensitivos con el propósito de estudiar la distribución de la pérdida de la sensación y la forma progresiva de la recuperación.

En 1929 Forsmann se introdujo un catéter hasta el ventrículo derecho y verificó su colocación mediante una placa de RX que se tomó después de caminar un trecho, inclusive tuvo que subir una escalera. Por este osado experimento y por su investigaciones subsiguientes mereció el premio Nobel de Medicina en 1956 (3-6).

\section{Exterminio de los prisioneros judíos}

Particularmente la comunidad judía era acusada de ser responsable de la depresión económica de Alemania en 1929 y de ser una raza inferior, culpable de la muerte de Jesucristo, que se mezclaba con la raza aria. En "Los Protocolos del Antiguo Zión" originado en Rusia en 1905 pero difundido por todo el mundo, se les acusaba de adelantar una conspiración internacional para dominar el mundo. Todos estos argumentos habían fortalecido el antisemitismo en Alemania y sirvieron de plataforma a
Hitler para congregar a millones de votantes alrededor del Partido Nacional Socialista.

Cuando comenzó la II Guerra Mundial en septiembre de 1939, el Ejército alemán ocupó la mitad occidental de Polonia, con lo cual casi dos millones de judíos polacos cayeron bajo la esfera de su poder. Se les obligó a trasladarse a guetos rodeados por muros y alambradas que en poco tiempo se convirtieron en campos de concentración a los cuales se les llamaba Campos de Trabajo Correctivo.

Con las sucesivas invasiones a países vecinos se crearon los campos de concentración de AuschwitzBirkenau, Bergen-Belsen, Buchenwald, Dachau, Trevlinka, Belzec, Semlin, Gross Rosen, Vught, etc. A estos pequeños territorios ubicados en Alemania, Polonia y parte de la que entonces era la Unión Soviética fueron llevados millones de prisioneros de los países europeos ocupados.

Unas cámaras de gas eran a base de monóxido de carbono, otras de cianuro, o de ácido clorhídrico y otras a base de "Zyklon B" sintetizado por los químicos alemanes, para poder matar con solo un cuarto de litro, a dos mil personas y a un costo de medio centavo por víctima. Auschwitz-Birkenau se constituyó en el mayor campo de exterminio ya fuera por hambre, por enfermedades sin tratamiento, por ejecuciones o por los inhumanos experimentos a que eran sometidos. En esta zona se construyeron enormes hornos crematorios para incinerar los cuerpos de las víctimas y borrar las huellas del exterminio. Luego que estos copaban su capacidad de 4.376 cadáveres por día, las cremaciones se realizaban al aire libre. Cuando terminó la Segunda Guerra Mundial unos 6’000.000 judíos, prisioneros soviéticos de guerra, eslavos, gitanos, trabajadores extranjeros, partisanos, homosexuales, testigos de Jehová, disidentes de las políticas del Reicht, comunistas y otros grupos indeseables fueron asesinados: unos 3'000.000 en centros de exterminio y en campos de trabajo, 1'400.000 en los fusilamientos masivos, y más de 1'600.000 en los guetos donde se realizaba experimentación en las diferentes formas de ejecución con crueldad. La mayor parte de los sacrificados en este holocausto eran de las comunidades judías de cada país invadido (7-12).

\section{Formas de experimentación con los prisioneros judíos}

Terminada la segunda guerra mundial en 1945, el mundo pudo darse cuenta de la magnitud, crueldad y frecuencia de los experimentos que los alemanes realizaban a judíos presos en los campos de concentración que fueron tratados como auténticos conejillos de indias.

Desde la década de los años 20 cuando Alemania era el centro cultural y artístico del mundo se discutían los nuevos conceptos sobre la evolución de la raza humana y se creaba una nueva ciencia: la Eugenia o Eugenesia. manipulación de la transmisión genética para mejorar la raza.

En 1934 Josef Mengele, estudiante de filosofía se unió al Partido Nazi. Luego de estudiar medicina en la Universidad de Frankfurt se vinculó al Instituto de Herencia Biológica e Higiene Racial donde el doctor Ottmar 
von Verschuer estudiaba la Ciencia Eugenésica para lo cual utilizaba niños gemelos.

Cuando el austríaco Adolf Hitler fue elegido jefe del Partido Nacional Socialista de los Trabajadores Alemanes, del cual se autoproclamó Führer (jefe), estaban en su plenitud entre la comunidad científica las teorías sobre la pureza hereditaria, la eutanasia, la esterilización de los indeseables y la manera de mantener la superioridad racial mediante la práctica de la eugenesia. A estas creencias se agregaba el antisemitismo (conjunto de políticas de rechazo a la raza judía) en torno al cual se fortaleció el poder de Hitler.

Una vez demostró Mengele que no tenía parientes judíos hasta la cuarta generación fue aceptado en las Schutz-Staffel o SS, "unidades defensivas" creadas por Hitler para vigilar y controlar el Partido Nacional-Socialista. Solicitó su traslado a los campos de concentración donde encontraría facilidades para continuar sus investigaciones. Durante su estancia en 1942 en el campo de Gross Rosen, en Silesia dirigió experimentos bacteriológicos con soldados soviéticos.

Por una coincidencia Mengele se encontró con Hans Otto Kahler, un médico y oficial de alto rango con quien había trabajado en experimentación con gemelos en el Instituto Vercheur en Frankfurt y que ahora trabajaba en Auschwitz-Birkenau. Esto determinó que este campo de concentración ubicado al sudeste de Polonia cerca de la ciudad de Cracovia, fuera un centro de experimentación desde 1943 donde Rascher, Kahler, Koenig, Scherpe. Klauber, Schumann, Kremer, Hirt, Bracht, Plotner, Schitz y otros 170 médicos dirigidos por Josef Mengele hicieran todo tipo de ensayos macabros con gemelos, sordos, enanos, gigantes, etc (7-12)

Congelación de prisioneros y exposición al calor: Estos experimentos solicitados por Himmler fueron dirigidos por el Dr. Sigmund Rascher en Auschwitz, Birkenau y Dachau. El propósito era establecer cuánto tiempo tardaba la mitad inferior del cuerpo en morir y la manera de revivirlo. Para ello introducían judíos o rusos desnudos en recipientes con hielo o los dejaban a la interperie hasta morir durante los períodos más fríos del invierno. Los sobrevivientes morían en las maniobras de descongelación durante los cuales se les irrigaban líquidos calientes por vía oral o por vía rectal.

Otros morían cuando eran llevados del frío intenso a altas temperaturas de manera súbita o viceversa, o cuando eran sometidos a lámparas de sol hasta quemarse.

Experimentos en gemelos: Puesto que uno de los principales objetivos de Hitler era obtener la pureza de la raza nórdica aria, los sujetos sometidos a mayor número de pruebas fueron los gemelos en quienes se realizaban macabros experimentos como animales de laboratorio. Se les tomaba medidas del cuerpo centímetro a centímetro y se les tomaban biopsias sin anestesia de diferentes vísceras antes y después de que se les sometiera a pruebas con agentes físicos, químicos y psicológicos.

Su consejero y amigo fue el profesor Otmar Freiherr von Verscheur, con quien mantenía correspondencia en su nuevo Instituto de Genética en Berlín. A uno o a ambos gemelos les extirpaba órganos o extremidades, los castraba o les relizaba cirugías para cambio de sexo. Como

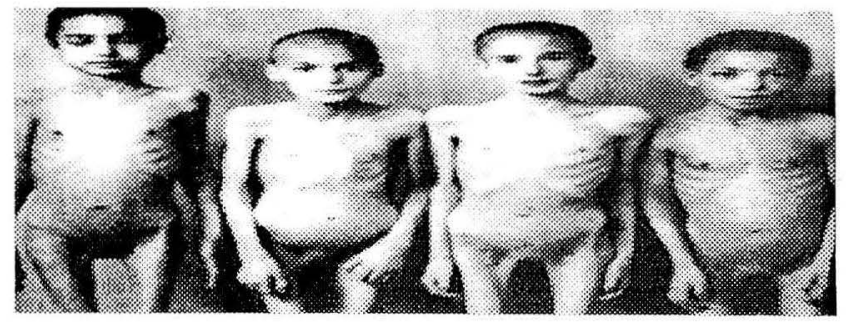

Gemelos, Archivo de Mengele Figura $0007 i(02$

estaba fascinado por los ojos azules constantemente les hacía inyección de colorantes en la cámara anterior de los niños de ojos de color diferente. El interés de Mengele en el genotipo humano rubio de ojos azules es curioso, pues ni él ni sus superiores tenían esos rasgos físicos.

Hacía transfusiones de sangre entre gemelos, les inyectaba en las venas diferentes extractos de enfermos y gérmenes letales, o fenoles, cloroformo, nafta, insecticidas, etc. A unos jóvenes les extirpaba las venas de las extremidades. Una sobreviviente relata como a su hermana gemela Mengele destrozó a martillazos una de sus manos. Supervisó una cirugía en la que dos gemelos fueron suturados para crear siameses. Eran frecuentes las vivisecciones sin anestesia y con las personas conscientes. Les hacía diferentes cirugías en la columna vertebral. Obviamente, nadie sobrevivía a sus tenebrosas cirugías o a sus secuelas.

Cada vez que hacía una nueva prueba inyectaba cloroformo en el corazón de ambos gemelos para asegurarse que morían al tiempo. Luego les hacía autopsia para ver los efectos sobre los órganos de sus experimentos genéticos. De esta forma, las ideas desquisiadas de Mengele cobraron hasta sesenta víctimas diarias. Se le conoció como el "Angel de la Muerte". De los 3.000 gemelos que pasaron por Auschwitz-Birkenau solo sobrevivieron $200 \mathrm{al}$ momento en que recibiera la orden de suspender los experimentos el 26 de Noviembre de 1944 debido al avance del ejército rojo de Rusia que tomaría posesión de este territorio.

Josef Mengele huyó a Italia en 1949 con documentos falsos; poco después llegó a Buenos Aires, donde encontraba seguridad pues en Argentina había una organización secreta conocida como ODESSA, encargada de otorgar salvoconductos a antiguos oficiales de las SS. En 1960, en Argentina tuvo lugar el secuestro del General Otto Eichmann a manos de un comando de la policía secreta israelí que lo llevó a la horca; esto produjo pánico a Mengele por lo cual se trasladó a Paraguay, país gobernado por el General Alfredo Stroessner, descendiente de alemanes y admirador de los nazis. Perseguido por los israelíes se radicó en el Brazil donde murió en 1979 ahogado en el mar por un infarto mientras se bañaba. Hubo dudas posteriores sobre la autenticidad de este cadáver cuando en 1983 los familiares de Mengele averiguaban qué le pasaría si fuera juzgado, pero las pruebas de $\mathrm{ADN}$ realizadas por varios gobiernos comprobaron la identidad del criminal de guerra más buscado por Alemania, Estados Unidos e Israel (7-12) 


\section{El código de Nüremberg y la declaración de Helsinki}

Esta ciudad alemana había sido sede en 1935 de la convención del Partido Nacional-Socialista. Allí se aprobaron las llamadas Leyes de Nüremberg, de tinte netamente rácial cuyo objetivo era despojar a los judíos alemanes de gran parte de sus derechos civiles. Con estas leyes se propagó la persecución hacia todos los judíos de los países que invadió Alemania durante la II Guerra Mundial. Durante el conflicto las tropas aliadas bombardearon la ciudad intensamente ya que en ella tenían su sede numerosas fábricas de aviones, submarinos y tanques. Finalizados los combates fue la sede del denominado "Proceso de Nüremberg", una serie de 13 juicios contra 185 militares, dirigentes y médicos nazis acusados de crímenes de guerra (1945-1946) ante un tribunal internacional formado por juristas de los países aliados. Durante este proceso se creó el concepto de "crímenes de guerra contra la humanidad".

Entre los acusados que fueron encontrados culpables, además de los grandes militares y dirigentes como $\mathrm{H}$. Göring y R.Hess, estaban las organizaciones de dominio civil como las SS (Schutz-Staffel), la Gestapo o Policía Secreta (Geheime Staatspolizei), las SA (SturmAbteilung), las SD o Servicios de Seguridad (SicherheitsDienst) y los médicos de las SS que pusieron sus conocimientos para realizar experimentos mortales y para procurar sufrimiento mediante torturas a enfermos y prisioneros de los campos de concentración. Unos médicos fueron condenados a muerte, 120 fueron condenados a prisión y 35 fueron absueltos. Hans Münch, médicomilitar absuelto demostró que postergaba los experimentos a los prisioneros para asegurar su supervivencia.

En 1945, durante los juicios por crímenes de guerra, el Tribunal de Nüremberg estableció el principio de responsabilidad individual para los causantes del holocausto. Al año siguiente, la Asamblea General de Naciones Unidas redactó la Convención para proscribir el genocidio, se produjo la promulgación del Código de Nüremberg en 1947 y la Declaración de Helsinki por parte de la Asociación Médica Mundial (AMM) en la XVIII Asamblea de Finlandia en 1964. Los lineamientos y condiciones impuestas a los futuros investigadores en dicho Código fueron ampliados a todo tipo de estudios en humanos en la siguiente Asamblea de la AMM reunida en Tokio en 1975 (que se conoce como Helsinki II ) (9-11).

Con base en el Código de Nüremberg, en la Declaración de Helsinki y en los consensos de los diferentes congresos mundiales de Etica en la Investigación Médica, se han formado grupos de bioética en cada país que han dado como resultado en Colombia la promulgación de normas de investigación emanadas del Ministerio de Salud y la conformación de Comités de Etica de manera obligatoria en las instituciones que avalan investigaciones en salud (7-12).

\section{Los experimentos en los Estados Unidos después de Nüremberg y Helsinki}

Los científicos y políticos de los Estados Unidos, quienes también suscribieron el Código de Nüremberg y la Declaración de Helsinki, líderes en la persecución a los criminales de guerra que experimentaban de manera infame con seres humanos, han permitido y fomentado estudios en los últimos 50 años que no se apartan mucho de los métodos utilizados en los campos de concentración de los nazis. Como ejemplo de los mismos están el estudio de Tuskegee y la exposición a diferentes formas de irradiación en seres humanos sanos y enfermos.

\section{El "Estudio Tuskegee" en pacientes negros sifilíticos}

En 1932 el Departamento de Salud Pública de los Estados Unidos empezó una evaluación de los habitantes negros del condado de Macon en Alabama donde el 82,4\% de los habitantes era de esta raza. Por esta época se calculaba que entre el $35 \%$ y el $38 \%$ de todos los enfermos de sífilis en el país estaban ubicados en esta región. Dicha evaluación dio luego un viraje hacia la simple observación del curso natural de la enfermedad en pacientes no tratados con todas sus complicaciones hasta la sífilis terciaria y la muerte. Nunca se redactó un protocolo de las estrategias a seguir en este estudio secreto ni se pidió consentimiento a los investigados. Una vez morían los pacientes se les sometía a cuidadosa necropsia para evaluar los estragos del Treponema sobre cada sistema del organismo. La excusa era conocer el comportamiento de esta patología en personas de raza negra. Se tomó como modelo un estudio previo realizado en Oslo, Noruega donde se había realizado un seguimiento similar en pacientes blancos con sífilis sin tratamiento entre 1891 y 1910.

El Hospital de Tuskegee ubicado en el condado de Macon en Alabama le dio el nombre a este estudio iniciado en 1932 y finalizado hacia 1972 con una cohorte de 412 pacientes de los cuales murieron 285 durante los 40 años de seguimiento. Se les mantuvo todo el tiempo solo con placebos a pesar de la introducción de la penicilina desde 1942 como tratamiento eficaz para el Treponema pallidum. Los encargados de ejecutar este programa ideado e implantado por autoridades del Departamento de Salud Pública fueron el Dr. Samuel J Brodus, el Dr. J. Douglas y la enfermera Eunice Evers (quien le dio el nombre a la película documental "Miss Evers's boys") (13).

En 1973 se dio a conocer al mundo el resultado de esa investigación en el Final Report of the Tuskegee Syphilis Study ad hoc Advisory Panel, Washington DC, Public Health Series. En 1974 el Senado de los Estados Unidos declaró el estudio como "atroz e intolerable", determinó la indemnización en dinero para los sobrevivientes y para los herederos de los fallecidos, pero no estableció ninguna sanción para quienes diseñaron y costearon esta penosa investigación (13-15).

Como conclusión de este episodio se publicó en 1979 el Belmont Report en el cual se fijaban tres bases de la ética de la Investigación:

1. El respeto a las personas, para ser tratadas como seres humanos

2. El principio de beneficencia, para producir el mínimo daño a los individuos investigados

3. El principio de justicia para la adecuada escogencia de las personas a investigar. 


\section{Experimentos con irradiación}

En diciembre de 1993 el Secretario de Energía de los Estados Unidos, Hazel $\mathrm{O}^{\prime}$ Leary, expuso un informe ante el Senado sobre los experimentos con irradiación en humanos realizados por la Comisión de Energía Atómica entre 1944 y 1974. En este período numerosos pacientes que buscaban ayuda en sus médicos de confianza en diferentes hospitales del país habían recibido inyecciones radiactivas de plutonio, uranio y polonio. Este estudio, llamado "Manhattan Project plutonium-injection experiments and related experimentation", se hizo con la excusa de prever los efectos deletéreos de la irradiación en trabajadores que manipulaban materiales para la elaboración de armas nucleares. A los pacientes investigados se les ocultó de manera absoluta sobre la administración de estas sustancias mortales y eran seguidos cuidadosamente durante años hasta que sobrevenía la muerte y se les realizaba la necropsia.

Con intenciones similares dos grupos de prisioneros de Washington y Oregon fueron sometidos a campos de irradiación con mínimos formatos de consentimiento. Simultáneamente la Universidad de Cincinnati experimentaba con radisótopos administrados mediante inyección o ingestión, tanto a niños como adultos que además eran sometidos a irradiación externa corporal total. El período de prueba se inició hacia 1945 y terminó en los primeros años de la década de los $70^{\circ} \mathrm{s}$. En otro protocolo, entre 1954 y 1960 fueron simplemente observados sin aviso de peligro todos los habitantes de las islas Marshall, irradiados de manera permanente como consecuencia de la explosión de una bomba de hidrógeno en el Pacífico. Igual ocurrió a la comunidad indígena sometida a radiaciones ionizantes pues habitaba los alrededores del reactor nuclear de Hanford en Washington (16).

Otro estudio llamado "Human Experiment 133" se realizó en pilotos y su tripulación que sobrevolaban entre 25 y 40 minutos a través de nubes de polvo radiactivo durante pruebas nucleares del Pacífico. La excusa del Departamento de Defensa era el conocimiento de los efectos de la eventual irradiación a la cual se someterían los astronautas en el espacio. Los resultados de estos estudios fueron publicados en el Final Report of the Advising Committee on Human Radiation Experiments (the ACHRE Report) (16)

\section{Los riesgos de la experimentación con fármacos}

En 1937, alrededor de 100 personas fallecieron por falla renal antes de ser retirada del mercado, como consecuencia de la comercialización por parte de Massengill Company, de un "elixir de sulfanilamida" disuelto en dietilenglicol.

En noviembre de 1937 la Secretaría de Agricultura de los Estados Unidos aprobó la norma de abstenerse de lanzar un medicamento al mercado sin que hubiera sido aprobado con base en la experiencia clínica. Al año siguiente todos los nuevos medicamentos quedaron bajo vigilancia de la Food and Drug Administration (FDA) para su aprobación. En 1947 el código de Nüremberg postuló el consentimiento voluntario sine qua non para la realización de experimentos en humanos. Más tarde se cambió el término por el de "consentimiento informado".

En 1952 fue publicado el primer libro sobre reacciones adversas: Meyler L. Side effects of drugs. Amsterdam: Elservier.

La Talidomida: El medicamento que más daño ha hecho en las últimas décadas es la talidomida que fue sintetizada en 1956 por la compañía alemana Chemie Grünental con el nombre de Contergan forte. A partir de 1958 salió al mercado en 11 países occidentales, 17 de Asia y 7 de África. Fue utilizado como hipnótico suave y se vendió como sedante para las náuseas, vómito y malestares del embarazo con una buena tolerancia aún a dosis mayores a las indicadas El primer apunte sobre el posible agente causal fue publicado el 16 de diciembre de 1961 en "The Lancet" como una carta al director, escrita por el médico australiano W.G. McBridel. En ella se sugería la relación entre el consumo de talidomida y la aparición de malformaciones congénitas.

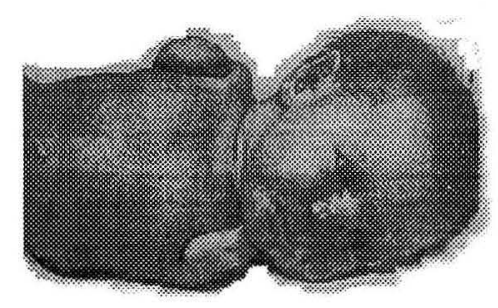

\begin{abstract}
Niña alemana con focomelia por Talidomida Figura 0007i03
\end{abstract}

Cinco años después de haber salido al mercado dejó entre 4.000 y 12.000 niños con malformaciones en todo el mundo, de los que aproximadamente el 15\% había fallecido en 1957, ya fuera por efecto del fármaco o en algunos casos por infanticidio a manos de las madres angustiadas. La Talidomida se retiró del mercado en el año de 1962.

Aunque con anterioridad ya se había descrito la teratogenicidad de ciertos antineoplásicos como la mustina y la aminopterina (1950) y también a consecuencia de la intoxicación por metilmercurio en la bahía de Minamata (1961), el impacto sobre la opinión pública del desastre de la talidomida fue mucho mayor. Este grave accidente motivó a la Organización Mundial de la Salud (OMS) a promover programas de vigilancia farmacológica con sistemas de notificación de las reacciones adversas de los medicamentos desde el año de 1962 (17-19).

En 1997 la FDA de Norteamérica aprobó la fabricación y venta de la Talidomida a la Compañía Farmacéutica Celgene Corp. de New Jersey (Thalidomid® tabl. X $100 \mathrm{mg}$ ) para ser usada en el eritema nodoso de la lepra y para las reacciones leprosas tipo II. Actualmente está en investigación para el lupus, úlceras del SIDA, liquen plano, etc. Se desconoce el mecanismo de acción intrín$\operatorname{seco}(5-6,17)$.

En enero de 1997 la FDA aprobó la experimentación no consentida en pacientes inconscientes en quienes la familia no pudiera aprobar o rechazar el tratamiento. 
Chuck Nolson califica esta norma como un permiso a la experimentación al estilo nazi (18).

\section{Necesidad de estudios controlados en animales y en humanos}

Los estudios que más han ayudado al avance de la investigación durante el último siglo en humanos han sido los experimentos. Es necesario su uso en grupos humanos bien vigilados y protegidos mediante protocolos dirigidos por científicos competentes previo uso en animales. Sin embargo, la historia de la investigación ha mostrado que aún a las puertas del siglo XXI los estudios experimentales conllevan algún grado de riesgo y hay intervenciones inocuas en animales que producen daño en humanos y viceversa. Otro aspecto difícil de prever es el efecto a largo plazo de los fármacos que actúan modificando la síntesis proteica a nivel del RNA y DNA, que pueden manifestarse con cambios fenotípicos de los descendientes.

\section{¿Tiene la ciencia derechos ilimitados sobre los anima- les de experimentación?}

Las sociedades defensoras de animales han llamado la atención sobre la exagerada experimentación en animales de manera cruel. Ha quedado clara la necesidad de experimentar con animales como una etapa previa para los medicamentos y otras formas de intervención para probar la inocuidad en ellos antes de llevarlos a grupos humanos. Pero con justa razón se cuestionan la vivisección sin anestesia, las descargas eléctricas, la exposición a otras fuentes de energía, la deprivación de alimentos y líquidos, la inyección de sustancias tóxicas, la producción artificial de enfermedades mortales, etc sin protocolos científicos estrictos, exentos de sadismo, que amplíen el conocimiento científico en aras del bienestar de la humanidad. Cuando una investigación comprometa animales debe consultarse la resolución 008430 del Ministerio de Salud de Colombia que en su título $\mathrm{V}$ ha reglamentado la investigación en este tipo de organismos vivientes para evitar los abusos, para que sean tratados como seres sensibles, merecedores de respeto y consideración por parte de los investigadores que hayan comprobado la importancia de su estudio para la salud humana o animal (20).

\section{El consentimiento informado}

Una de las fortalezas del código de Nüremberg, promulgado en 1947 y de la Declaración de Helsinki II (Artículos 1 a 9) en 1975, es la obligatoriedad del consentimiento voluntario después de recibir información clara y suficiente con la garantía de retirarse del estudio en cualquier momento sin sufrir por ello consecuencia alguna. Establece claramente que el consentimiento debe obtenerse libremente, sin presiones políticas, sociales, económicas o profesionales. En caso de investigaciones con niños, con personas incompetentes y con enfermos mentales el consentimiento debe otorgarse por el guardián legal o por el familiar más cercano (20).
El mismo código establece que solo pueden autorizarse como investigadores a científicos de capacidad reconocida y la necesidad de suspender los experimentos cuando en el curso de los mismos se haya detectado daño a los investigados, máxime si de antemano se conoce la posibilidad de muerte, invalidez o daño permanente. Respecto al mecanismo utilizado solo justifica el estudio cuando no se puedan obtener datos útiles a la humanidad por otro medio.

Algunos médicos siguen aferrados a la idea de que la baja instrucción de sus pacientes justifica la aplicación de medios diagnósticos o terapéuticos sin pedir la opinión de esas personas que "no entenderían el lenguaje técnico porque no han estudiado medicina". Por ejemplo, es obvio que usted no puede discutir con un paciente las ventajas o la inconveniencia de extraerle los ganglios obturatrices si tiene un carcinoma de cérvix IB. Pero si usted propone una investigación en la cual se elimina este paso, debe discutirlo no con la paciente ni sus familiares, sino con los expertos en esta enfermedad y ante los miembros del Comité de Etica de la entidad que avala su investigación con respaldo científico adecuado y suficiente para que se puedan prever resultados benéficos desde antes de empezar el estudio. Aún así, una vez haya recibido aprobación de su propuesta por parte de los evaluadores, debe explicar en lenguaje sencillo a cada paciente sobre su participación en esta investigación, aceptar su rechazo o lograr su aceptación de acuerdo con las normas establecidas por el Ministerio de Salud de Colombia.

$$
\begin{array}{r}
\text { Los derechos y el bienestar del individuo deben siempre } \\
\text { prevalecer sobre los derechos de la sociedad y de la ciencia. } \\
\text {-Declaración de Helsinki (Finlandia) 1964- } \\
\text { y Tokio (Japón)1975- }
\end{array}
$$

\section{Reglamento de la investigación en Colombia}

Desde 1976 la Organización Mundial de la Salud inició la elaboración de guías internacionales para la investigación biomédica en seres humanos. Después de reuniones de expertos en diferentes ciudades del mundo, se establecieron las pautas modelo para cada país. Colombia adoptó estas recomendaciones y elaboró la resolución 008430 del 4 de Octubre de 1993 sobre normas científico-administrativas para la investigación en salud, que debe ser de obligatoria consulta en las facultades de Medicina, en organizaciones oficiales o no gubernamentales como los laboratorios farmacéuticos que realicen o avalen investigaciones, en las revistas médicas y en general en todas las instituciones involucradas de cualquier manera en un estudio con seres humanos (20).

\section{Reglamento del manejo e investigaciones del VIH, SIDA y ETS}

El decreto 1543 del 12 de Junio de 1997 del Ministerio de Salud de Colombia, reglamenta el manejo e investigaciones sobre pacientes con el virus de la inmunodeficiencia humana (VIH), sobre el síndrome de la inmunodeficiencia adquirida (SIDA) y sobre las otras enfermedades de transmisión sexual. 
En el capítulo IV de dicho decreto reglamenta y estimula la investigación en este campo de las infecciones, sujeta a la Declaración de Helsinki dictada por la Federación Médica Mundial. Las normas anteriores al decreto 1543 eran muy restrictivas para los investigadores del VIH y SIDA (21).

\section{Los comités de ética de las universidades y de los hospitales}

El cumplimiento de los requisitos de un protocolo atañe no solo a los expertos en el área de la investigación respectiva. También a los Comités de Etica que deben velar por los fundamentos científicos de la propuesta con base en los principios de la Declaración de Helsinki.

La resolución 008430 del Ministerio de Salud reglamenta la creación y funcionamiento de los Comités de Etica de la Investigación, acoge todos los principios promulgados en Nüremberg, Helsinki y Tokio sobre el respeto a la dignidad de los sujetos en estudio, sobre la selección de la muestra, sobre los once requisitos del consentimiento informado (Título II, capítulo 1, artículo 15), sobre la investigación en comunidades, en menores de edad y discapacitados, en mujeres embarazadas, en embriones y fetos, en grupos subordinados, sobre el uso de nuevas tecnologías, sobre la investigación de ácidos nucleicos y recombinantes, con sustancias radiactivas y sobre investigación con animales (20)

No es posible establecer una línea divisoria entre los aspectos científicos y éticos de un protocolo. Unos conllevan a los otros: se violan los principios de la ética cuando el diseño de un estudio en humanos no permite llegar a conclusiones útiles, o se enfrenta a riesgos no justificados, o propone gastos suntuosos que se aparten de los medios y fines de la investigación.
Las responsabilidades básicas de los Comités de Etica de las Universidades, Hospitales y demás entidades que avalan investigaciones de salud son:

1. Verificar que las intervenciones propuestas tengan suficiente respaldo en la literatura médica disponible (medicina basada en la evidencia).

2. Que haya sido evaluada por un comité de expertos en el área de estudio

3. Asegurar que las consideraciones técnicas y éticas que se derivan de los protocolos presentados por jóvenes investigadores que realizan su post-grado en las áreas médico-quirúrgicas sean vigiladas estrechamente por investigadores de reconocida capacidad científica.

El concepto escrito del Comité de Etica no debe ser de ninguna manera un paso protocolario de última hora. Estos Comités deben ser asesores desde las primeras etapas del diseño de la investigación y aunque su mayor aporte es en el campo de la bioética, deben vigilar sobre los errores de diseño que pongan en riesgo a la entidad que avala el estudio desde el punto de vista legal en caso de que sobreviniera un accidente o se presentara un efecto indeseado como consecuencia de la intervención a que se somete al individuo o grupo lesionado.

\section{Conclusiones finales}

Existen reales posibilidades de abuso de la investigación si no es realizada o vigilada por entidades y personas de reconocida solvencia científica y moral, con los propósitos nobles de mejorar el conocimiento de las leyes que rigen el ciclo de vida y los fenómenos y fuerzas de la naturaleza; como proponía Teilhard de Chardin: para colaborar con el orden y la armonía del universo.

La vigilancia de los Comités de Etica son la garantía de que cada individuo recibirá el trato con la dignidad que usted deseara si fuera el investigado.

\section{BIBLIOGRAFIA}

1. Organización Mundial de la Salud. Bioética. Edit OPS, Washington, 1990.

2. Non ethic experimentation on humans. http://donut.mit.edu/dmaze/ human-experimentation. shtml/

3. Tejerizo LC. Etica en la Investigación. Rev Española Obstet. Ginecol. 1979; 38(244): 191-195.

4. Rueda PG. Etica en la Investigación Médica. Medicina (Academia Nacional de Medicina de Colombia). Sept 1989; 20: 24-27.

5. Gracia D. Etica de los confines de la vida. Edit. Búho Santafé de Bogotá. No hay referencia al año de publicación.

6. Porter JK. Etica en la Investigación Clínica. Gaceta Med. México, 1983; 119(3): 97-129.

7. Muller-Hill B. From Daedalus to Mengele: the dark side of human genetics. Genome 1989; 31(2): 876-8.

8. Posner GL., Ware J. Mengele: the complete story. McGraw Hill. Nyork, 1986.

9. Laguados M., Dekes C. Children of the flames. Edit William Morrow, N. York 1991.

10. Campo de Concentración: Enciclopedia Microsoft Encarta 1998. Búsqueda por palabras claves: holocausto, Partido Nacional-Socialista, etc.
11. The camps of concentration. www.candles-museum.com/camps.htm

12. Hitler byography: www.candles-museum.com/HITLER.HTM

13. Documento fílmico "Miss Every's boys", director Joseph Sargent, HBO.

14. Belmont Report about Tuskegee Sudy: www.brown.edu/ Administration/ Research Administration/bemont/belmont.html

15. Final Report of the Tuskegee Syphilis Study ad hoc Advisisory Panel. Washington DC, U.S. Public Health Series, 1973.

16. Government document about Radiation "http://tisnt.eh.doe.gov/ohre/ roadmap/ achre/intro.html

17. Strom BL. Pharmacoepidemiology, 2nd edition. Chichester: John Wiley \& Sons, 1994.

18. New Rules of FDA: www.breakpoint.org

19. Matos EL. Farmacoepidemiología, Xunta de Galicia, Servicio de Saúde, Santiago de Compostela, 1995.

20. Ministerio de Salud de Colombia. Resolución 008430 de Octubre 4 de 1993. Normas científicas y administrativas para la investigación en salud.

21. Ministerio de Salud de Colombia. Decreto 1543 del 12 de Junio de 1997 sobre la infección por el VIH, el SIDA y las otras ETS. 